\title{
D-cycloserine Deters Reacquisition of Cocaine Self-Administration by Augmenting Extinction Learning
}

\author{
Bríd Á Nic Dhonnchadha', Jonathan J Szalay', Cindy Achat-Mendes², Donna M Platt², Michael W Otto', \\ Roger D Spealman ${ }^{2}$ and Kathleen M Kantak*,' \\ 'Department of Psychology, Boston University, Boston, MA, USA; ${ }^{2}$ Division of Behavioral Biology, New England Primate Research Center, Harvard \\ Medical School, Southborough, MA, USA
}

\begin{abstract}
Augmentation of cue exposure (extinction) therapy with cognitive-enhancing pharmacotherapy may offer an effective strategy to combat cocaine relapse. To investigate this possibility at the preclinical level, rats and squirrel monkeys were trained to self-administer cocaine paired with a brief visual cue. Lever pressing was subsequently extinguished by withholding cocaine injections while maintaining responsecontingent presentations of the cue. The glycine partial agonist D-cycloserine (DCS; 15 and $30 \mathrm{mg} / \mathrm{kg}$ in rats, 3 and $10 \mathrm{mg} / \mathrm{kg}$ in monkeys) was evaluated for its effects on the rate of extinction and subsequent reacquisition of cocaine self-administration. Compared with vehicle, pretreatment with $30 \mathrm{mg} / \mathrm{kg}$ DCS $0.5 \mathrm{~h}$ before extinction training reduced the number of responses and latency to reach the extinction criterion in rats, but neither dose of DCS altered these measures in monkeys. In both species, pretreatment with the higher dose of DCS before extinction training significantly attenuated reacquisition of cocaine self-administration compared with either extinction training in the absence of DCS or DCS in the absence of explicit extinction. Furthermore, treatment with $30 \mathrm{mg} / \mathrm{kg}$ DCS accompanied by brief handling (a stress induction) immediately after but not $6 \mathrm{~h}$ after extinction training attenuated reacquisition of cocaine self-administration in rats. No adverse effects of $10 \mathrm{mg} / \mathrm{kg}$ DCS were evident in quantitative observational studies in monkeys. The results suggest that DCS augmented consolidation of extinction learning to deter reacquisition of cocaine self-administration in rats and monkeys. The results suggest that DCS combined with exposure therapy may constitute a rational strategy for the clinical management of cocaine relapse. Neuropsychopharmacology (2010) 35, 357-367; doi:I0.1038/npp.2009. I39; published online 9 September 2009
\end{abstract}

Keywords: cocaine; cognitive enhancer; D-cycloserine; extinction training; relapse; self-administration

\section{INTRODUCTION}

Relapse to drug-seeking and drug-taking behaviors is a common manifestation of cocaine addiction and perhaps the most serious impediment to effective treatment (O'Brien, 2003). Repeated pairings of cocaine use with environmental cues (eg, drug paraphernalia and context of drug administration) result in conditioning and memory consolidation, such that later exposure to the cues alone may induce craving and relapse (Lu et al, 2006). There are as yet no approved medications to treat cocaine addiction, although several forms of cognitive-behavioral therapy have shown efficacy (Dutra et al, 2008). An additional strategy that has promise is exposure therapy targeting conditioned drug cues (O'Brien et al, 1990). Through an extinction training process whereby cocaine cues are repeatedly presented in the absence of cocaine, exposure therapy

*Correspondence: Dr KM Kantak, Department of Psychology, Boston University, 64 Cummington Street, Boston, MA 02215, USA, Tel: 617353 920I, Fax:617 353 2894, E-mail: kkantak@bu.edu Received 14 May 2009; revised 8 August 2009; accepted 10 August 2009 may promote new learning that counters the motivating impact of cocaine-related cues (Havermans and Jansen, 2003). Exposure therapy has not been effective consistently as a stand-alone treatment for cocaine relapse. This might reflect the context-dependent nature of extinction therapy (Conklin and Tiffany, 2002; Ressler et al, 2004) as well as cocaine-induced dysfunction of memory systems critical for effective extinction learning and consolidation (Franklin et al, 2002; Makris et al, 2004; Quirk and Mueller, 2008). The development of medications to augment exposure therapy for substance abuse is therefore of high priority.

Extinction is an active learning process that encompasses many of the neural substrates that subserve other forms of learning and memory (Bouton, 2004). These processes involve increased neurotransmission and plasticity at central glutamatergic synapses (Kelley, 2004). Animal studies have identified $N$-methyl-D-aspartate (NMDA) receptors as key mediators of the acquisition and consolidation of cocaine-cue associations, as well as in its extinction and reconsolidation (Feltenstein and See, 2007; Milton et al, 2008; Zweifel et al, 2008). Thus, the potential of an NMDA-based pharmacotherapy to enhance cocaine-cue extinction learning and consolidation would constitute a 
significant advancement in the treatment of cocaine addiction.

The cognitive-enhancing drug D-cycloserine (DCS) is a partial agonist at the strychnine-insensitive glycine site of NMDA receptors that enhances glutamate neurotransmission (Bowery, 1987; Hood et al, 1989). Recent studies demonstrated the facilitatory effects of DCS on the extinction of conditioned fear in laboratory animals (Walker et al, 2002; Ledgerwood et al, 2003; Ledgerwood et al, 2004) and specific forms of anxiety in humans (Ressler et al, 2004; Hofmann et al, 2006; Otto et al, 2009b, in press [b]). DCS also can facilitate extinction of behavior controlled by cocaine cues as assessed in the conditioned place preference paradigm in rodents (Botreau et al, 2006; Paolone et al, 2009; Thanos et al, 2009).

In this study, we investigated whether the combination of DCS with extinction training could alter learned associations between cocaine and a cocaine-paired stimulus in rats and monkeys with histories of persistent cocaine selfadministration. To assess the impact of DCS on cocaine cue extinction learning and consolidation, DCS was administered either $0.5 \mathrm{~h}$ before, immediately after, or $6 \mathrm{~h}$ after extinction training. These time points were based on results suggesting that DCS acts primarily during the acquisition and consolidation phases of extinction learning (Davis et al, 2006). Previous studies demonstrated that DCS-facilitated extinction of conditioned fear in rats when administered immediately before or soon after extinction training (Walker et al, 2002; Ledgerwood et al, 2003). In contrast, DCS administered $4 \mathrm{~h}$ after extinction training, which surpasses the theoretical timeframe for NMDA-dependent memory consolidation (Dash et al, 2004), had no effect on extinction of conditioned fear (Ledgerwood et al, 2003). In addition, previous studies have shown that arousal is necessary for post-training memory consolidation, possibly as a result of glucocorticoid release (McGaugh and Roozendaal, 2009). Acute handling is a mild stressor that induces release of corticosterone in rats (Roman et al, 2004). Thus, we evaluated if arousal in the form of brief handling promoted DCS facilitation of cocaine-cue extinction consolidation in rats.

Consistent with the interpretation that DCS augments consolidation of extinction learning, Ledgerwood et al (2005) reported that DCS administered in the absence of explicit extinction training does not alter conditioned fear. We therefore also investigated the effects of DCS administered before a cocaine self-administration session and before a session during which levers were removed from the experimental chamber and cocaine and cocaine cues withheld, thus preventing explicit extinction of the conditioned cocaine cue. Finally, adverse effects were monitored in monkeys treated with DCS and assessed by measuring a range of unconditioned behaviors predictive of potential drug side effects.

\section{MATERIALS AND METHODS}

\section{Subjects}

Twenty-eight male rats (Crl(WI)BR; 275-300 g) separated into three cohorts and nine male squirrel monkeys (Saimiri sciureus; 760-940 g) separated into two cohorts were used.
Housing, animal care, surgical procedures, and experimental chambers were as described previously (Kantak et al, 2005; Platt et al, 2005; Supplementary Methods). Before study initiation, rats were experimentally naive, whereas monkeys had previous cocaine self-administration experience. Before surgery, rats were trained to lever press for $45 \mathrm{mg}$ food pellets. Rats and monkeys were maintained in accordance with the Guide for Care and Use of Laboratory Animals (Institute of Laboratory Animal Resources, Commission on Life Sciences, National Research Council, National Academy Press, Washington, DC, 2003) and with the guidelines of the Committee on Animals of Harvard Medical School. Research protocols were approved by the Boston University and Harvard Medical School Institutional Animal Care and Use Committees.

\section{Drugs}

Cocaine $\mathrm{HCl}$ (National Institute on Drug Abuse, Bethesda, MD or Sigma-Aldrich, St Louis, MO) was dissolved in sterile $0.9 \%$ saline for intravenous selfadministration. DCS base (Sigma-Aldrich) was dissolved in sterile $0.9 \%$ saline (vehicle) and injected through intraperitoneal (rats) or intramuscular (monkeys) routes of administration in volumes $\leqslant 1 \mathrm{ml} / \mathrm{kg}$ of body weight.

\section{Procedure}

Experiment 1: effects of DCS administered before extinction training. Rats $(n=7)$ were trained ( $2 \mathrm{~h}$ sessions) to press a lever to obtain $0.3 \mathrm{mg} / \mathrm{kg}$ intravenous injections of cocaine and simultaneous activation of a distinctive visual stimulus (2-s light change) under a fixed-ratio (FR) reinforcement schedule for which each completion of five responses produced an injection (Kantak et al, 2005). Rats underwent several cycles of baseline self-administration sessions followed by extinction and reacquisition test sessions, to obtain within-subject dose-response data for DCS (15 and $30 \mathrm{mg} / \mathrm{kg}$ ) and vehicle pretreatment. Injections were administered $0.5 \mathrm{~h}$ before the extinction training session. Lever pressing was extinguished by withholding cocaine injections, while maintaining response-contingent presentations of the cocaine-paired stimulus. Each extinction training session lasted until lever pressing declined to $<10 \%$ of the baseline response rate for $0.5 \mathrm{~h}$. The order of DCS dose testing was different across rats in the three cycles to minimize potential confounds of repeated testing. DCS dose selection was based on previously published work in rats (Walker et al, 2002; Ledgerwood et al, 2003; Woods and Bouton, 2006). Four days after extinction training and without further DCS treatment, rats underwent an extinction retention test session lasting $1.5 \mathrm{~h}$. During the four intervening days, between extinction training and the retention test, rats remained in their home environments. One day after the retention test, reacquisition of cocaine self-administration in the absence of DCS pretreatment was evaluated. Reacquisition tests were conducted using conditions identical to those in the cocaine self-administration baseline phase, and no drug priming or other inducements to initiate lever pressing were given. Between cycles, rats self-administered cocaine for a minimum of 2 weeks (see Supplementary Figure S1 for a schematic of Experiment 1). 
One rat died of an unrelated cause before testing with $15 \mathrm{mg} / \mathrm{kg}$ DCS could be conducted.

Monkeys $(n=5)$ were trained ( $1-1.5 \mathrm{~h}$ sessions) under a second-order reinforcement schedule, in which completion of 10 responses (FR unit) produced the 2-s visual stimulus, and the first FR unit completed after the lapse of $5 \mathrm{~min}$ produced a cocaine injection $(0.3 \mathrm{mg} / \mathrm{kg}$ intravenous) paired with the 2-s visual stimulus (Platt et al, 2001). As in rats, monkeys underwent several cycles of baseline self-administration sessions followed by extinction and reacquisition test sessions to obtain within-subject doseresponse data for DCS (3.0 and $10.0 \mathrm{mg} / \mathrm{kg}$ ) and vehicle pretreatment. Studies in monkeys used the same design as specified above for rats. DCS dose selection was based in part on previously published work in rhesus monkeys (Rupniak et al, 1992; Matsuoka and Aigner, 1996; Schneider et al, 2000). Pilot observational studies confirmed that 3.0 and $10.0 \mathrm{mg} / \mathrm{kg}$ DCS could be administered safely to squirrel monkeys. Between cycles, monkeys self-administered cocaine for a minimum of 2 weeks.

Experiment 2: effects of DCS administered before test sessions without extinction training. To determine whether reacquisition of cocaine self-administration was altered when DCS was administered in the absence of extinction training, the same cohort of monkeys used in Experiment 1 was evaluated under a control condition in which DCS $(10 \mathrm{mg} / \mathrm{kg})$ was injected $0.5 \mathrm{~h}$ before a cocaine self-administration session rather than an extinction session. In a second control condition, a new cohort of rats ( $n=7$ per group) was trained to self-administer cocaine for a minimum of 3 weeks and then injected with either DCS $(30 \mathrm{mg} / \mathrm{kg})$ or vehicle $0.5 \mathrm{~h}$ before placement into the chambers with the levers retracted and without presentation of either the cocaine-paired stimulus or the delivery of cocaine. The duration of this session was time-yoked to rats used in Experiment 1, and subjects were matched as closely as possible for baseline rates of responding. For both control conditions, the equivalent of an extinction retention session was conducted 4 days later, and the equivalent of a reacquisition test was initiated on the following day as described above (see Supplementary Figure S1 for a schematic of Experiment 2).

Experiment 3: effects of DCS administered after extinction training. The cohort of rats used in Experiment 2 was examined further in two additional test cycles to evaluate the effects of DCS administered after an extinction training session. Each cycle consisted of a minimum of 2 weeks of baseline cocaine self-administration followed by a session of extinction training that lasted until lever pressing declined to $<10 \%$ of the baseline response rate for $0.5 \mathrm{~h}$. In the first test cycle, either DCS $(30 \mathrm{mg} / \mathrm{kg})$ or vehicle was injected immediately after extinction training, and rats $(n=7$ per group; randomly selected from subjects used in the previous cycle) were returned directly to their home cages. In the last test cycle, either DCS $(30 \mathrm{mg} / \mathrm{kg})$ or vehicle again was injected immediately after extinction training, but this time the injections were administered in conjunction with $3 \mathrm{~min}$ of gentle handling before returning the rats $(n=7$ per group; randomly selected from subjects used in the previous cycle) to their home cages.
A final new cohort of rats was trained to self-administer cocaine $(n=6)$ and then injected in a counterbalanced order with either DCS $(30 \mathrm{mg} / \mathrm{kg})$ or vehicle using two test cycles. Injections were administered in conjunction with $3 \mathrm{~min}$ of handling, $6 \mathrm{~h}$ after the extinction training session ended. Rats remained in their home cages in the interim. For each condition, the extinction retention and reacquisition tests were conducted as described above (see Supplementary Figure S1 for a schematic of Experiment 3).

Experiment 4: effects of DCS on unconditioned behavior. Using quantitative observational techniques (Platt et al, 2000), the behavioral effects of DCS were assessed in squirrel monkeys under the conditions that promote a repertoire of behaviors that is sensitive to potential side effects of drug treatments. A new cohort of monkeys $(n=4)$ initially was habituated to an observation arena and then tested in a counterbalanced order with $10 \mathrm{mg} / \mathrm{kg}$ DCS and vehicle; tests were separated by $>2$ weeks. The scoring system included 10 behavioral categories (Supplementary Table S1), which were scored by recording the presence or absence of each behavior in $15 \mathrm{~s}$ intervals during $5 \mathrm{~min}$ sampling periods (Platt et al, 2000). In addition, during the 6 th, 18th, and 30th min of each session, the monkey was removed from the observational arena by a trained handler and evaluated for ataxia (defined as the inability to balance on and/or grasp a stainless steel pole $(56 \mathrm{~cm}$ in length; $1 \mathrm{~cm}$ in diameter) held horizontally) and muscle resistance (defined as a change in resistance to hindlimb extension). For ataxia, a score of 0 indicated that the monkey was able to balance normally, a score of 1 indicated inability to balance effectively, and a score of 2 indicated that the monkey could neither balance on nor grasp the pole. For muscle resistance, a score of 0 indicated no change in resistance to hindlimb extension, a score of +1 indicated increased resistance to extension and/or clinging to the grid floor, and a score of -1 indicated decreased resistance to extension and/or flaccidity.

\section{Data Analyses}

Data were analyzed separately for rats and monkeys. The last five cocaine self-administration sessions were used to establish the baseline rate of responding on the active lever for each cycle. As there was a 15-fold range in baseline response rates during cocaine self-administration sessions in individual monkeys (0.13-2.0 responses/s) and an 8.5-fold range in individual rats (0.02-0.17 responses/s), responding during extinction retention and reacquisition tests were expressed as percent of baseline response rates for each cycle.

For analysis of the extinction training session, measures used were total responses on the active lever and the latency to attain the extinction criterion. Mixed-model ANOVA was performed for each experiment. Treatment differences were determined by post hoc Dunnett's $t$-test for multiple comparisons, regardless of the outcome of the overall F-value (Winer 1971). Where appropriate, Student's $t$-test for dependent or independent samples was used. 


\section{RESULTS}

\section{Experiment 1: Effects of DCS Administered Before Extinction Training}

This experiment was conducted to determine if DCS administered before extinction training could augment extinction learning and deter reacquisition of cocaine selfadministration in rats and monkeys. Within each species, baseline rates of cocaine-maintained responding were statistically similar across the treatment cycles (Figure 1, top panels). Treatment with DCS before extinction training altered significantly the number of extinction responses $\left(\mathrm{F}_{(2,12)}=7.7 ; p \leqslant 0.007\right)$ and the latency to the extinction criterion $\left(\mathrm{F}_{(2,12)}=7.9 ; p \leqslant 0.007\right)$ in rats (Figure 1, left middle panels) but not in monkeys (Figure 1, right middle panels). Dunnett's $t$-test revealed that rats treated with $30 \mathrm{mg} / \mathrm{kg}$ DCS showed significantly fewer responses $(p \leqslant 0.01)$ and exhibited a significantly shorter latency to reach the extinction criterion $(p \leqslant 0.01)$ relative to the vehicle control. Extinction training response curves, on the basis of sequential 10-min bins, are shown in Supplementary Figure S2 for individual rats and monkey. During the extinction retention session conducted 4 days later, responding was statistically similar across all three pretreatment conditions in both species (Figure 1, bottom panels).

Treatment with DCS before extinction training attenuated significantly reacquisition of cocaine self-administration in both rats and monkeys (Figure 2, top and bottom panels). Subjects treated with vehicle or the lower dose of DCS $(15 \mathrm{mg} / \mathrm{kg}$ in rats; $3 \mathrm{mg} / \mathrm{kg}$ in monkeys) reacquired baseline rates of cocaine-maintained responding on session 1 or 2 , whereas subjects treated with the higher dose of DCS $(30 \mathrm{mg} / \mathrm{kg}$ in rats; $10 \mathrm{mg} / \mathrm{kg}$ in monkeys) reacquired baseline rates of cocaine-maintained responding after session 3. Thus, reacquisition responses were analyzed over the first three sessions. ANOVA indicated that dose was not a significant factor for either rats or monkeys. On the basis of Dunnett's $t$-test, earlier treatment with the highest dose of DCS $(30 \mathrm{mg} / \mathrm{kg}$ in rats; $10 \mathrm{mg} / \mathrm{kg}$ in monkeys) significantly reduced responding compared with the vehicle control for reacquisition sessions 1,2 , and 3 in rats and reacquisition sessions 1 and 3 in monkeys $(p \leqslant 0.05)$.

\section{Experiment 2: Effects of DCS Administered Before Test Sessions Without Extinction Training}

This experiment was conducted to determine whether effective doses of DCS $(30 \mathrm{mg} / \mathrm{kg}$ in rats; $10 \mathrm{mg} / \mathrm{kg}$ in monkeys) could alter reacquisition of cocaine self-administration if DCS injection was not combined with explicit extinction training. The first control condition, in which DCS was administered before a cocaine self-administration session rather than an extinction session, was evaluated in monkeys. At baseline, the average response rate maintained by self-administration of cocaine was $0.38 \pm 0.07$ responses/s. The $10 \mathrm{mg} / \mathrm{kg}$ dose of DCS did not significantly alter the rate of responding when administered before a selfadministration session ( $94 \pm 28 \%$ of baseline). During the retention session conducted 4 days later, the rate of responding was $30 \pm 7 \%$ of baseline, which is similar to the level of
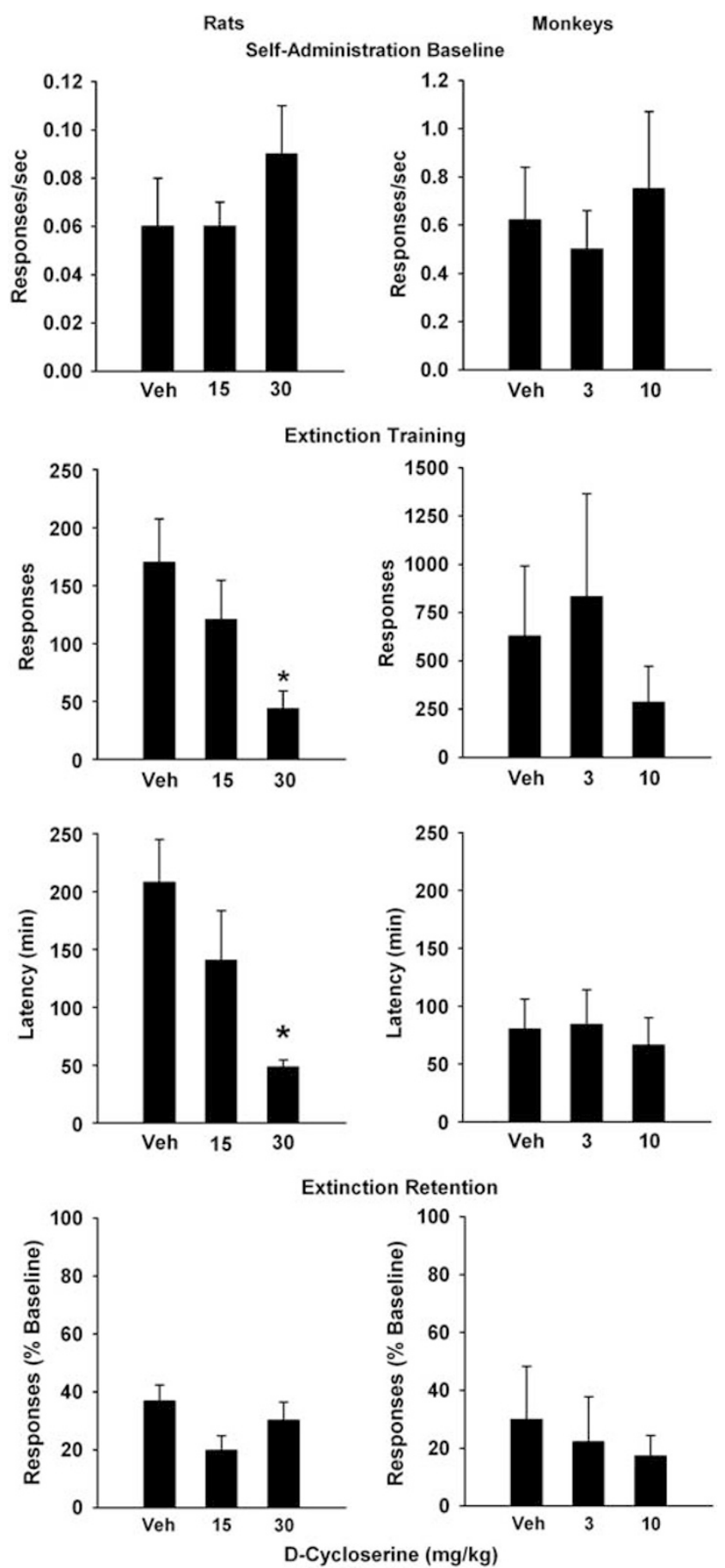

Figure I Effects of DCS and vehicle (Veh) administered before extinction training (Experiment I) in rats (left panels) and monkeys (right panels). Values are the mean \pm SEM response rates during cocaine selfadministration baseline sessions (top panels), lever responses during extinction training sessions and the latency to reach the extinction criterion (middle panels), and percent of baseline lever responses during extinction retention sessions (bottom panels). No statistically significant differences between conditions were found during self-administration baseline or extinction retention sessions in rats or monkeys (Dunnett's $t$-test, $p \leqslant 0.10$ $0.78)$. $*$ Significantly less than the corresponding Veh control pretreatment $(p \leqslant 0.0 I)$.

responding in vehicle-treated monkeys undergoing extinction training ( $30 \pm 19 \%$ of baseline). Analysis of the lever pressing during the first three reacquisition sessions 

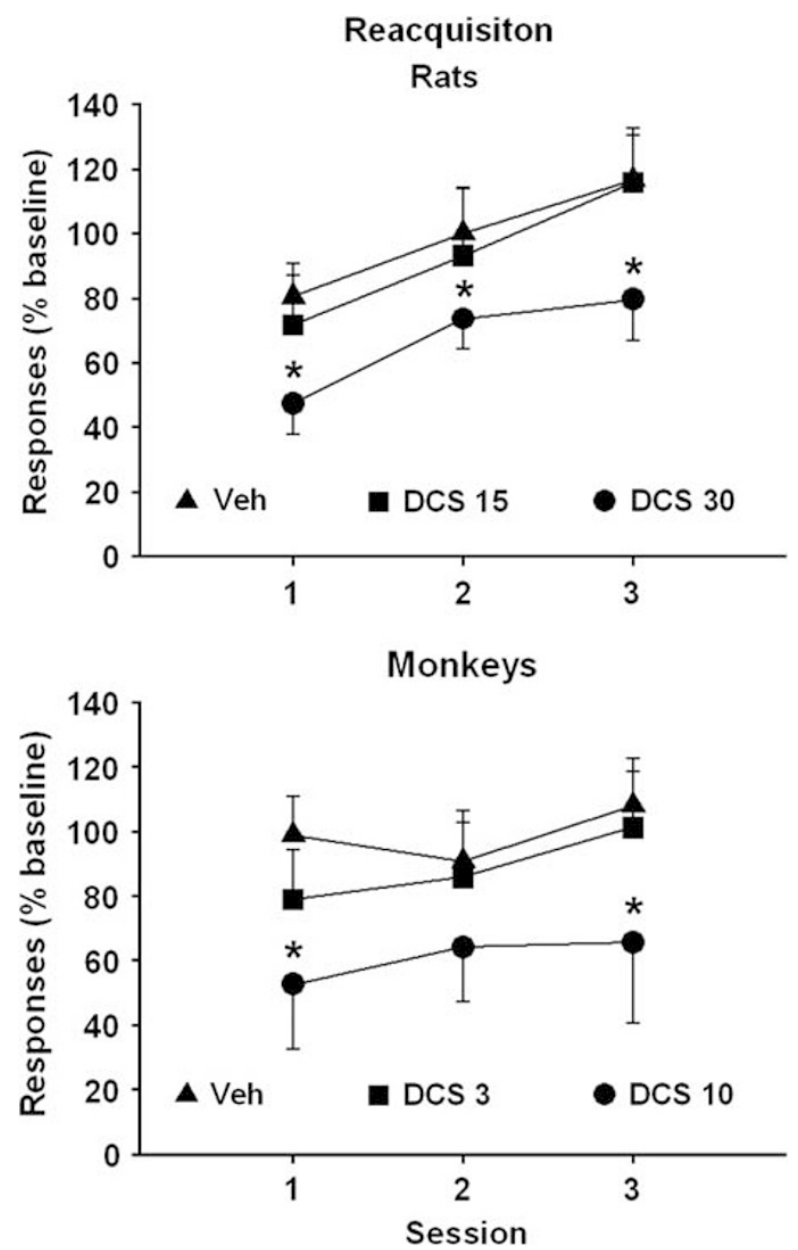

Figure 2 Effects of DCS and vehicle (Veh) administered before extinction training (Experiment I) on subsequent reacquisition of cocaine self-administration in rats (top panel) and monkeys (bottom panel). Values are the mean \pm SEM percent of baseline lever responses. * Significantly less than the corresponding Veh control pretreatment $(p \leqslant 0.05)$.
(Figure 3, left panel) revealed that responding for the cocaine self-administration control condition was emitted at approximately baseline levels and was significantly greater than responding when the same dose of DCS was administered before extinction training in Experiment 1 ( $p \leqslant 0.05$ by Student's $t$-test for dependent samples).

The control condition under which the levers were retracted and neither cocaine nor the cocaine-paired stimulus was presented (no-extinction session) was evaluated in rats. At baseline, the average response rate maintained by self-administration of cocaine was identical under both conditions $(0.04 \pm 0.01$ responses/s). During the retention session, which was conducted 4 days later, administration of $30 \mathrm{mg} / \mathrm{kg}$ DCS before the no-extinction session resulted in a rate of responding $(99 \pm 13 \%$ of baseline) that was similar to the rate engendered by administration of vehicle before the no-extinction session ( $94 \pm 19 \%$ of baseline). During reacquisition, the vehicle and $30 \mathrm{mg} / \mathrm{kg}$ treatment groups reacquired baseline rates of cocaine self-administration within 2 sessions. Analysis of the averaged values for the first three reacquisition sessions (Figure 3, right panel) revealed that responding by the rats that received $30 \mathrm{mg} / \mathrm{kg}$ DCS but no extinction training was emitted at approximately baseline levels and was significantly greater than responding when the same dose of DCS administered before extinction training in Experiment 1 ( $p \leqslant 0.05$ by Student's $t$-test for independent samples). Thus, for both species DCS was effective in deterring reacquisition of cocaine self-administration only when combined with explicit extinction training.

\section{Experiment 3: Effects of DCS Administered after Extinction Training}

This experiment determined if effective doses of DCS altered reacquisition of cocaine self-administration when DCS was administered after rather than before extinction

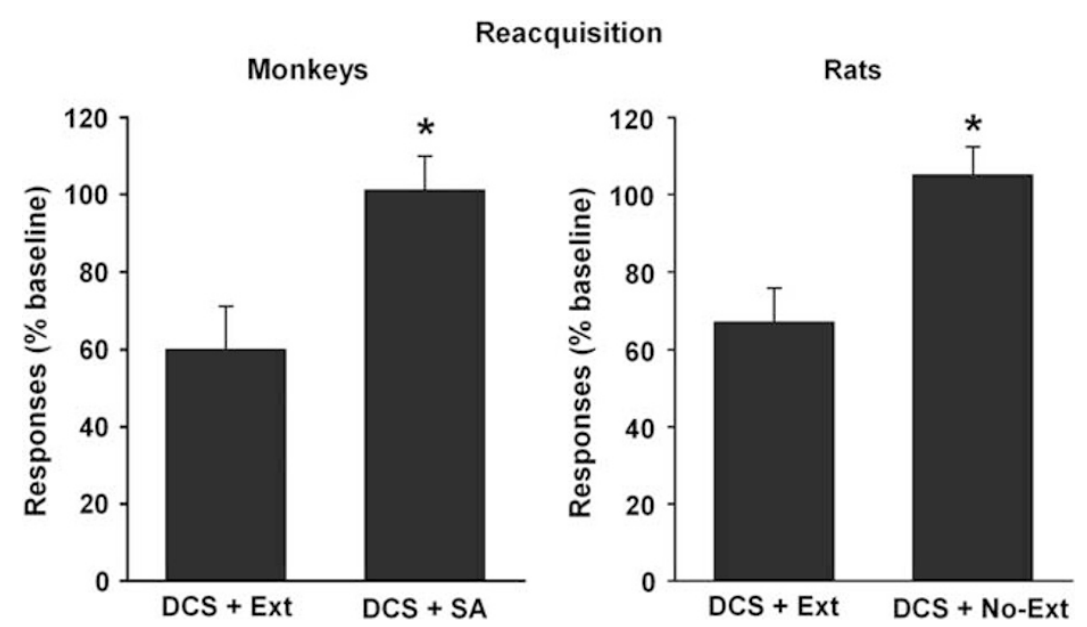

Figure 3 Effects of DCS administered prior to sessions without extinction training (Experiment 2) on subsequent reacquisition of cocaine selfadministration. Values are the mean \pm SEM percent of baseline responses during reacquisition sessions in monkeys (left panel) injected with $10 \mathrm{mg} / \mathrm{kg}$ DCS before a cocaine self-administration (SA) session, and in rats (right panel) injected with $30 \mathrm{mg} / \mathrm{kg}$ DCS before a no-extinction (no-Ext) session. * Significantly greater than the DCS + extinction (Ext) training condition $(p \leqslant 0.05)$. 

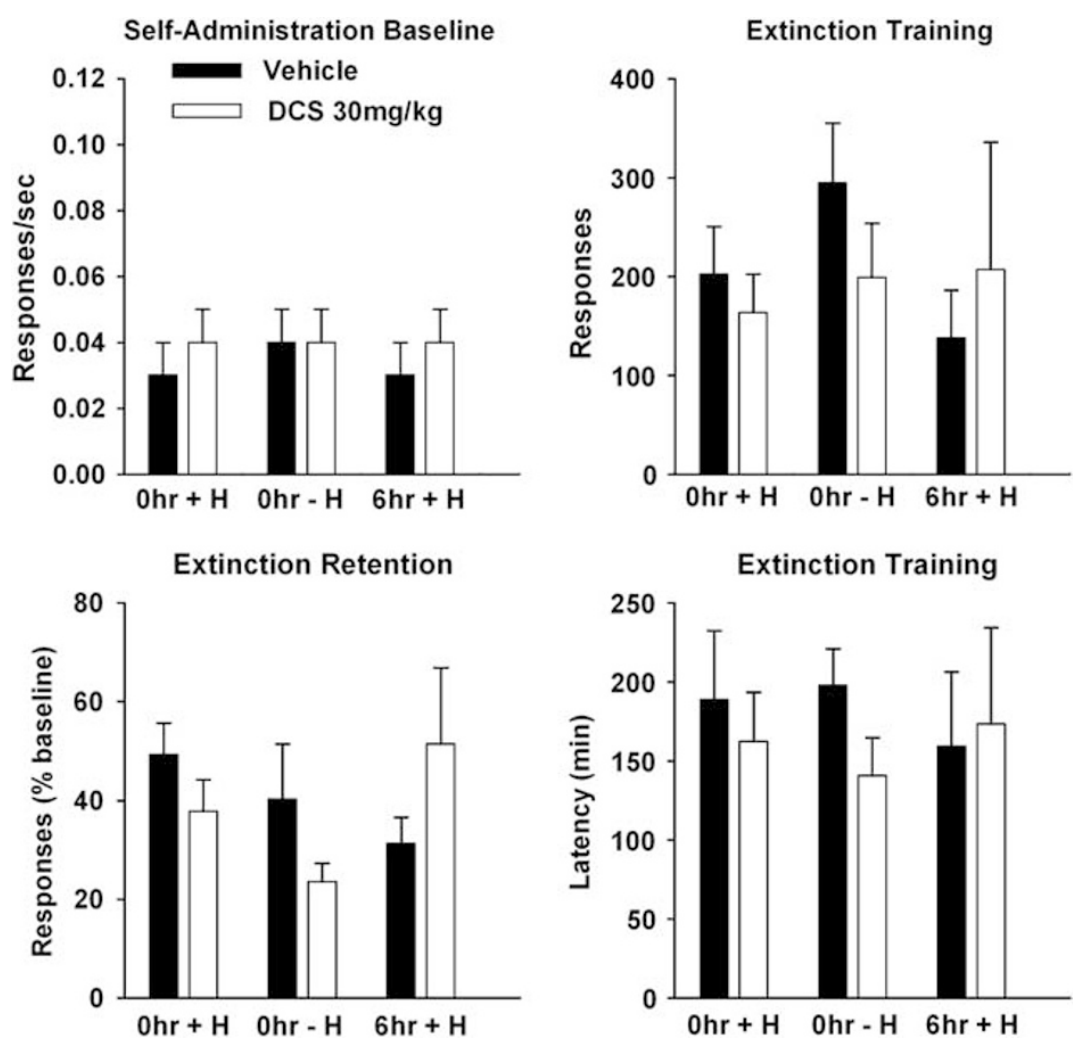

Figure 4 Effects of DCS $(30 \mathrm{mg} / \mathrm{kg})$ and vehicle $(V e h)$ administered immediately after extinction training (Experiment 3) with brief handling $(0 \mathrm{~h}+\mathrm{H})$ or without brief handling $(0 \mathrm{~h}-\mathrm{H})$ and $6 \mathrm{~h}$ after extinction training in conjunction with brief handling $(6 \mathrm{~h}+\mathrm{H})$. Values are the mean \pm SEM response rates during cocaine self-administration baseline sessions (top left panel), lever responses during extinction training sessions and latency to reach the extinction criterion (right panels), and the percent of baseline responses during extinction retention sessions (bottom left panel). No statistically significant differences between conditions were found during self-administration baseline, extinction training, or extinction retention sessions (independent samples $t$-test, $p \geqslant 0.12-0.85$ ).

training in rats. Baseline rates of cocaine self-administration (Figure 4, top left panel) as well as the number of responses and latency to attain the extinction criterion (Figure 4, right panels) did not differ significantly between groups under the three experimental conditions. During the extinction retention session conducted 4 days following extinction training, responding also was statistically similar compared across the vehicle and $30 \mathrm{mg} / \mathrm{kg}$ DCS treatments under the three experimental conditions (Figure 4, bottom left panel).

Injection of $30 \mathrm{mg} / \mathrm{kg}$ DCS immediately after extinction training with brief handling attenuated significantly the reacquisition of cocaine self-administration (Figure 5, top panel). Rats treated with vehicle immediately after extinction training reacquired baseline rates of responding during the first reacquisition session, whereas rats treated with $30 \mathrm{mg} / \mathrm{kg}$ DCS did not consistently reacquire baseline rates of responding until after session 5. Thus, reacquisition responses were analyzed over the first five sessions. ANOVA revealed that dose was a significant factor $\left(\mathrm{F}_{(1,12)}=6.4\right.$, $p \leqslant 0.027)$. On the basis of Dunnett's $t$-test, administration of $30 \mathrm{mg} / \mathrm{kg}$ DCS produced significant reductions in the rate of responding during reacquisition sessions 1,4 , and 5 relative to vehicle administration ( $p \leqslant 0.01$ or $p \leqslant 0.05$ ).

In contrast, $30 \mathrm{mg} / \mathrm{kg}$ DCS administered either immediately after extinction training without brief handling or $6 \mathrm{~h}$ after extinction training with brief handling did not affect reacquisition of cocaine self-administration (Figure 5, middle and bottom panels). ANOVA over the first five reacquisition sessions in each experiment did not reach statistical significance. Dunnett's $t$-test confirmed that the effects of DCS and vehicle treatments did not differ significantly under either experimental condition.

\section{Experiment 4: Effects of DCS on Unconditioned Behavior}

Examination of the effects of DCS under conditions that promote a varied repertoire of behavior in squirrel monkeys show that, compared with vehicle, $10 \mathrm{mg} / \mathrm{kg}$ DCS produced a decrease in scratching that was not significant relative to vehicle control and had no appreciable effect on any other behavioral measure (Table 1). Thus, the effect of DCS on extinction and subsequent reacquisition of cocaine selfadministration did not appear to be secondary to druginduced impairment of motor function or the emergence of behavioral side effects that could interfere with lever pressing.

\section{DISCUSSION}

\section{Effects of DCS on Extinction Learning: Acquisition vs Consolidation}

The principal finding of this study is that administration of DCS in conjunction with extinction training deterred 

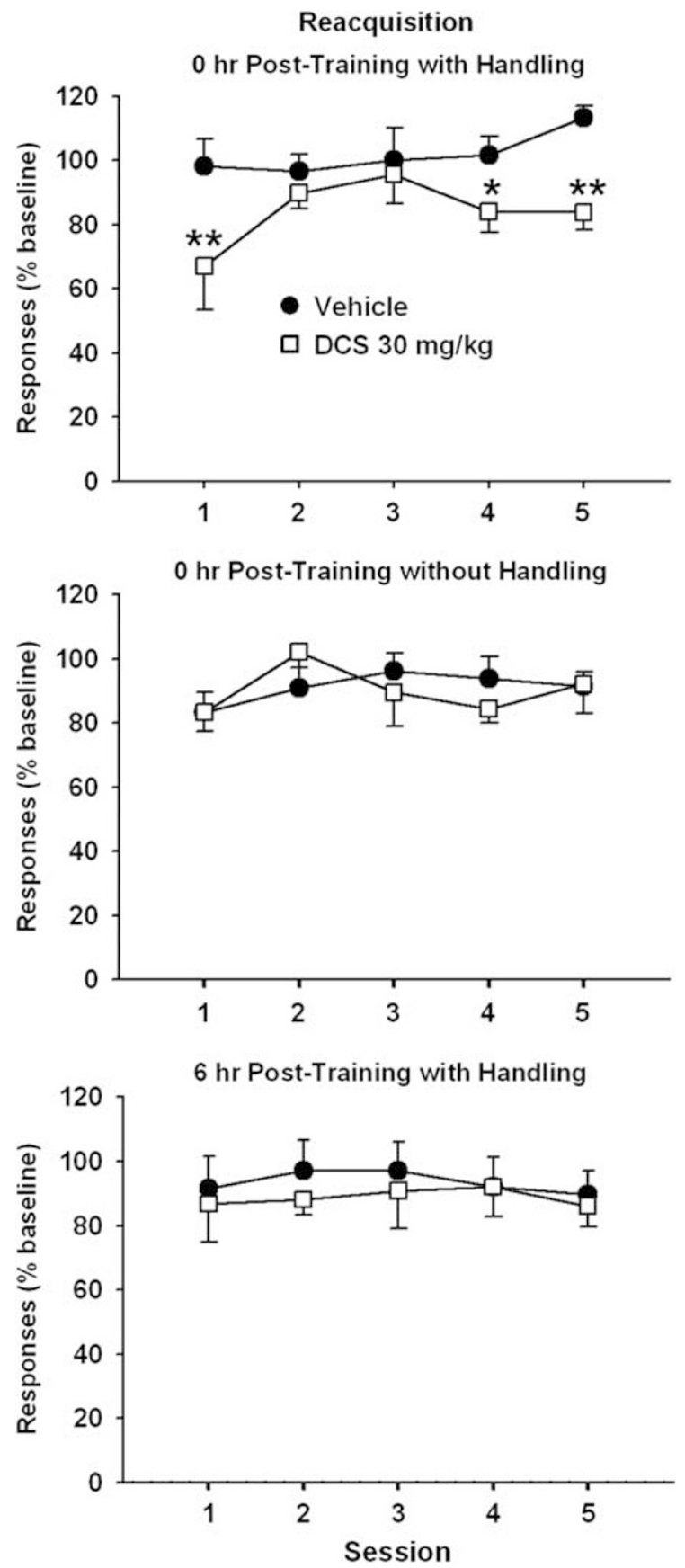

Figure 5 Effects of DCS $(30 \mathrm{mg} / \mathrm{kg})$ and vehicle (Veh) administered after extinction training (Experiment 3) on subsequent reacquisition of cocaine self-administration in rats. Values are the mean \pm SEM percent of baseline lever responses for DCS or Veh administered immediately after extinction training in conjunction with brief handling (top panel); immediately after extinction training without brief handling (middle panel); and $6 \mathrm{~h}$ after extinction training in conjunction with brief handling (bottom panel). Significantly less than the corresponding Veh control pretreatment $(* p \leqslant 0.05$ and $* * * 0.01)$.

reacquisition of cocaine self-administration in rats and monkeys. The within-subject design used in our studies is similar to designs used in many human laboratory studies on drug abuse (eg, Haney and Spealman 2008) and is advantageous because it requires fewer subjects than conventional group designs to draw meaningful conclusions. Although
Table I Absence of Effects of $10 \mathrm{mg} / \mathrm{kg}$ DCS on Observable Behaviors in Squirrel Monkeys

\begin{tabular}{lcc}
\hline Behavior & \multicolumn{2}{c}{ Modified frequency score } \\
\cline { 2 - 3 } & Vehicle & DCS \\
\hline Locomotion & $9.3 \pm 1.7$ & $8.9 \pm 1.7$ \\
Object manipulation & $5.2 \pm 0.6$ & $6.1 \pm 1.3$ \\
Foraging & $0.2 \pm 0.1$ & $0.3 \pm 0.1$ \\
Grooming & $1.8 \pm 0.8$ & $1.2 \pm 0.2$ \\
Scratching & $2.6 \pm 0.8$ & $0.3 \pm 0.2$ \\
Vocalization & $2.0 \pm 1.5$ & $1.8 \pm 1.3$ \\
Sleep posture & 0 & 0 \\
Static posture & 0 & 0 \\
Procumbent & 0 & 0 \\
Visual scan & $19.3 \pm 0.6$ & $18.3 \pm 1.0$ \\
Ataxia & 0 & 0 \\
Muscle resistance & 0 & 0 \\
\hline
\end{tabular}

the use of within-subject designs in extinction-related studies may lead to interpretative constraints, we minimized such constraints in the current study by randomizing to the extent possible the order in which doses were tested across animals, limiting the number and frequency of extinction tests, and providing sufficient time between tests to fully re-establish stable self-administration. Furthermore, the use of an FR schedule in rats and a second-order schedule in monkeys permitted evaluation of the generality of the effects of DCS combined with cocaine-cue extinction training in different species with different behavioral histories of cocaine self-administration. The complimentary findings using these two species, schedules of reinforcement and methods for pairing the visual stimulus with cocaine (intermittent vs. non-intermittent), suggest that administration of DCS combined with extinction training promoted new learning that countered the impact of the previously conditioned cocaine cue rather than the reinforcing effect of cocaine per se.

Consistent with this interpretation, pretreatment with DCS before a self-administration control session rather than an extinction training session in monkeys did not reduce cocaine self-administration during the session or alter subsequent reacquisition after 4 days of cocaine abstinence. In addition, the effects of DCS administered before extinction training on reacquisition cannot be attributed to general behavioral disruption, as DCS did not induce impairment of motor function or induce significant side effects in monkeys. An additional control experiment in rats further showed that DCS did not alter reacquisition of cocaine self-administration when DCS was administered before a session in which the levers were retracted and cocaine and cocaine cues were withheld (ie, in the absence of explicit extinction training. Collectively, the results of our control experiment in rats and monkeys are consistent with the well-documented finding that DCS reduces conditioned fear only when administered in the context of explicit extinction training (Walker et al, 2002; Ledgerwood et al, 2003; Ledgerwood et al, 2005). 
In this study, several cycles of testing were used and DCS was shown to be effective, regardless of the cycle in which it was injected. Recently, Langton and Richardson (2008) reported that DCS was not effective in augmenting extinction of fear conditioning when the drug was administered before a second cycle of extinction training. However, only 5 days separated the first and second cycles of extinction training, and there was only a single reconditioning (shock + cues) session between the two cycles. In our study, repeated cycles of testing were separated by at least 2 weeks of stable cocaine self-administration and the sequential tests for individual subjects were randomized to the extent possible. Under these conditions, we saw no obvious indication of diminished extinction or reacquisition as a function of sequential tests, suggesting that the repeatedmeasures design we used afforded relatively independent assessments of the effects of DCS and vehicle across the testing cycles.

There are two main pieces of evidence to suggest that DCS may attenuate reacquisition of cocaine self-administration by augmenting consolidation of extinction learning rather than by facilitating the rapidity of extinction. First, although the effects of DCS during extinction training in rats are in accordance with the underlying assumption that DCS may facilitate acquisition of extinction learning (Walker et al, 2002; Ledgerwood et al, 2003), it was evident in this study that attenuated responding during subsequent reacquisition tests did not depend exclusively on the rapidity of extinction as the latter measure was not significantly affected by DCS administration in monkeys. Although this finding could reflect differences in the way that DCS affects learning processes in rodents compared with primates, DCS pretreatment has been shown previously to have cognitiveenhancing effects on recognition and spatial memory in monkeys (Matsuoka and Aigner 1996; Schneider et al, 2000). Alternatively, as the extinction criterion typically was reached more rapidly in monkeys than in rats during vehicle control tests (Figure 1, middle panels), facilitation of extinction learning by DCS may have been obscured in the study with monkeys. However, in fear conditioning studies in rats, DCS has not been shown to facilitate within-session extinction as found in this study (Ledgerwood et al, 2003; Woods and Bouton, 2006; Bouton et al, 2008). Facilitation of within-session extinction by DCS in Experiment 1 may have resulted from the lengthy extinction training session coupled with a larger number of conditioned stimulus presentations.

A second piece of evidence suggesting that DCS may have attenuated reacquisition of cocaine self-administration by augmenting consolidation of extinction learning comes from experiments in which DCS was administered after extinction training. Post-training manipulations have proven to be a useful procedure for assessing drug effects on memory consolidation (McGaugh and Roozendaal, 2009). In our experiments, administration of DCS with brief handling immediately after extinction training resulted in a significant attenuation of cocaine self-administration reacquisition, whereas DCS administered in the same way $6 \mathrm{~h}$ after extinction training had no systematic effect on reacquisition. These results are consistent with findings from the fear conditioning literature showing that posttraining administration of DCS significantly augments extinction of conditioned fear only if given within a critical window of time (Ledgerwood et al, 2003, 2004). Administration of DCS $4 \mathrm{~h}$ after extinction training, for example, failed to enhance extinction of conditioned fear (Ledgerwood et al, 2003), and similar results have recently been reported for extinction of cocaine-conditioned place preference (Botreau et al, 2006; Paolone et al, 2009).

\section{Role of Arousal in the Effects of DCS on Consolidation of Extinction Learning}

Converging evidence suggests that arousal and accompanying release of endogenous glucocorticoids is critical for post-training memory consolidation (McGaugh and Roozendaal, 2009), and elevated levels of glucocorticoids at the end of extinction training may be an important factor for observing augmented consolidation of extinction learning by post-training administration of DCS (Yang et al, 2007). In tests of fear conditioning in rats, for example, plasma corticosterone levels are significantly elevated for over $45 \mathrm{~min}$ after the extinction training session ends, which likely provides sufficient arousal to promote augmented consolidation of fear extinction learning by either pre- or post-training DCS administration (Guijarro et al, 2007). In contrast, in rats with a history of cocaine self-administration, plasma corticosterone levels are elevated primarily during the early stage of extinction training and then return to basal levels as the session progresses (Goeders and Clampitt, 2002). Thus, the ability of DCS administered before extinction training to augment consolidation of cocaine-cue extinction learning may be assisted by the increased level of arousal and glucocorticoid release during the early portion of the extinction training sessions. However, enhanced consolidation of cocaine-cue extinction learning by DCS administered after the session would be difficult to achieve unless critical arousing stimulation is provided post-training. Brief handling in rats is a mild stressor that increases plasma corticosterone levels (Roman et al, 2004) and augments consolidation of fear extinction learning (Hui et al, 2006). Although rats in this study were handled daily during each experiment, the additional $3 \mathrm{~min}$ of handling following extinction training was novel, and as such, an unfamiliar procedure that likely induced mild arousal. It is clear from the literature that intense arousal and high levels of corticosterone are disruptive to memory consolidation (McGaugh and Roozendaal, 2009). In future studies it might, therefore, be informative to exploit other models of stress and arousal (eg, tail pinch or bodily restraint) to assess the generality of our finding with postsession handling.

\section{Effects of DCS on Extinction Retention}

As DCS administration before extinction training is thought to facilitate new learning that counters the motivating impact of conditioned stimuli (Davis et al, 2006), we expected that the magnitude of responding during the extinction retention sessions would be decreased by earlier administration of DCS in conjunction with extinction training. This expectation was not met, however, as the rate of responding during the extinction retention session was similar after DCS and vehicle treatment under all experimental 
conditions in both species. One possible explanation for this finding is that responding during the extinction retention session may reflect the criterion used during the extinction training session; ie, extinction training continued until the individual subject's response rate was $<10 \%$ of the baseline response rate for $0.5 \mathrm{~h}$, regardless of pretreatment (DCS or vehicle). With all subjects receiving functionally equivalent levels of extinction training, it may have been difficult to detect DCS-facilitated extinction learning during the retention session.

A second possible explanation may relate to differences in the way DCS influences extinction of responses controlled by a fear cue $v s$ responses controlled by a cocaine cue. In fear conditioning studies, DCS administration before extinction training consistently resulted in greater extinction retention during post-extinction tests in which the fearprovoking conditioned stimulus also was presented (Walker et al, 2002; Ledgerwood et al, 2003). In contrast, Paolone et al (2009) reported that extinction retention was not systematically affected by earlier DCS or vehicle treatment administered during extinction training in which rats were confined to cocaine- and saline-paired compartments. Interestingly, despite equivalent levels of extinction retention in that experiment, reinstatement of a conditioned preference following a cocaine priming injection was attenuated in rats that had received DCS during extinction training. These findings correspond remarkably with those of the present study in which rats and monkeys were pretreated with DCS before extinction training and later showed attenuated responding during the reacquisition test but not the extinction retention test.

Reasons for the apparently different effects of DCS on extinction retention for fear $v s$ cocaine cues are not entirely clear, but may be related to context specificity of extinction learning. For example, Woods and Bouton (2006) demonstrated that DCS-facilitated extinction when tests took place in the same environmental context as extinction but not in the original conditioning environment, leading to the idea that extinction of fear is highly context-specific. In the conditioned place preference procedure used by Paolone et al (2009) and the present experiment, all phases of the study (conditioning, extinction, and testing) were conducted in the same environmental context. A potentially important clinical implication of our results is that DCS combined with cue exposure therapy might not be effective in reducing cue reactivity in addicts if therapy only is provided in an environment that is distinct from (ie, in a clinic or laboratory) the environment where drugs are typically self-administered. This may be an important consideration when designing clinical treatment strategies. It should be noted, however, that it may not be necessary to extinguish all discrete cues that are predictive of drug as it was demonstrated that DCS facilitation of extinction to one discrete conditioned stimulus generalized to facilitation of extinction to another discrete conditioned stimulus that was never paired with DCS (Ledgerwood et al, 2005).

\section{CONCLUSIONS}

Our findings show that a single injection of DCS combined with extinction training deters subsequent reacquisition of cocaine self-administration in rats and squirrel monkeys.
DCS treatment in conjunction with extinction training is more enduring for attenuating reacquisition compared with either extinction training in the absence of DCS or DCS in the absence of extinction training. Consistent with the view that memory consolidation is time-dependent and requires arousal (McGaugh and Roozendaal, 2009), the benefit of DCS was evident when the drug was administered either before extinction training or immediately after extinction training in conjunction with brief handling. In addition to the timing of DCS and arousal, the duration of cocaine-cue exposure may be critical for DCS facilitation of extinction consolidation. Recently, DCS administration following a single brief $(30 \mathrm{~min})$ episode of cocaine-cue exposure was shown to enhance subsequent cocaine-seeking by augmenting reconsolidation of cocaine-cue memory (Lee et al, 2009). Furthermore, it is possible that multiple extinction training sessions combined with DCS treatment might produce even greater cocaine-cue extinction consolidation. For example, clinical studies administering DCS in combination with two or three spaced sessions of exposure therapy have demonstrated long-term benefits of this combined treatment approach for reducing anxiety disorders (Norberg et al, 2008). This combined approach may be aided by arousal and glucocorticoid activity during treatment (Otto et al, 2009, in press [a]). Collectively, the results provide a potential framework for implementing human studies to evaluate the efficacy of exposure therapy combined with DCS pharmacotherapy for the clinical management of cocaine relapse.

\section{ACKNOWLEDGEMENTS}

This study was funded by Grants R01 DA024315, R01 DA11054, P51 RR00168, and T32 MH020064. The content is solely the responsibility of the authors and does not necessarily represent the official views of the National Institutes of Health. We thank Ms Kristen Bano, Ms Shana Langer, Ms Nicole McKenzie, Ms Laura Teixeira, and Ms Audrey Wells for assistance with data collection.

\section{DISCLOSURE}

The authors declare that BND, CA-M, DP, RS, and JS, except for income received from their primary employers, have received no financial support or compensation from any individual or corporate entity over the past 3 years for research or professional service and there are no personal financial holdings that could be perceived as constituting a potential conflict of interest. The authors declare that over the past 3 years, KK has received consulting fees and stock options from Yaupon Therapeutics, the developer of therapeutics for central nervous system disorders and that MO has received consulting fees and grant support from Organon (Schering-Plough) and advisory board service for Jazz Pharmaceuticals, the developers of therapeutics for central nervous system disorders.

\section{REFERENCES}

Botreau F, Paolone G, Stewart J (2006). D-cycloserine facilitates extinction of a cocaine-induced conditioned place preference. Behav Brain Res 172: 173-178. 
Bouton ME (2004). Context and behavioral processes in extinction. Learn Mem 11: 485-494.

Bouton ME, Vurbic D, Woods AM (2008). D-cycloserine facilitates context-specific fear extinction learning. Neurobiol Learn Mem 90: $504-510$.

Bowery NG (1987). Glycine-binding sites and NMDA receptors in brain. Nature 326: 338.

Conklin CA, Tiffany ST (2002). Applying extinction research and theory to cue-exposure addiction treatments. Addiction 97: 155-167.

Dash PK, Hebert AE, Runyan JD (2004). A unified theory for systems and cellular memory consolidation. Brain Res Brain Res Rev 45: 30-37.

Davis M, Ressler K, Rothbaum BO, Richardson R (2006). Effects of $\mathrm{D}$-cycloserine on extinction: translation from preclinical to clinical work. Biol Psychiatry 60: 369-375.

Dutra L, Stathopoulou G, Basden SL, Leyro TM, Powers MB, Otto MW (2008). A meta-analytic review of psychosocial interventions for substance use disorders. Am J Psychiatry 165: 179-187.

Feltenstein MW, See RE (2007). NMDA receptor blockade in the basolateral amygdala disrupts consolidation of stimulus-reward memory and extinction learning during reinstatement of cocaine-seeking in an animal model of relapse. Neurobiol Learn Mem 88: 435-444.

Franklin TR, Acton PD, Maldjian JA, Gray JD, Croft JR, Dackis CA et al (2002). Decreased gray matter concentration in the insular, orbitofrontal, cingulate, and temporal cortices of cocaine patients. Biol Psychiatry 51: 134-142.

Goeders NE, Clampitt DM (2002). Potential role for the hypothalamo-pituitary-adrenal axis in the conditioned reinforcer-induced reinstatement of extinguished cocaine seeking in rats. Psychopharmacology (Berl) 161: 222-232.

Guijarro JZ, Tiba PA, Ferreira TL, Kawakami SE, Oliveira MG, Suchecki D (2007). Effects of brief and long maternal separations on the HPA axis activity and the performance of rats on context and tone fear conditioning. Behav Brain Res 184: 101-108.

Haney M, Spealman R (2008). Controversies in translational research: drug self-administration. Psychopharmacology (Berl) 199: 403-419.

Havermans RC, Jansen AT (2003). Increasing the efficacy of cue exposure treatment in preventing relapse of addictive behavior. Addict Behav 28: 989-994.

Hofmann SG, Meuret AE, Smits JA, Simon NM, Pollack MH, Eisenmenger $\mathrm{K}$ et al (2006). Augmentation of exposure therapy with D-cycloserine for social anxiety disorder. Arch Gen Psychiatry 63: 298-304.

Hood WF, Compton RP, Monahan JB (1989). D-cycloserine: a ligand for the $N$-methyl-D-aspartate coupled glycine receptor has partial agonist characteristics. Neurosci Lett 98: 91-95.

Hui IR, Hui GK, Roozendaal B, McGaugh JL, Weinberger NM (2006). Posttraining handling facilitates memory for auditorycue fear conditioning in rats. Neurobiol Learn Mem 86: 160-163.

Kantak KM, Udo T, Ugalde F, Luzzo C, Di PN, Eichenbaum HB (2005). Influence of cocaine self-administration on learning related to prefrontal cortex or hippocampus functioning in rats. Psychopharmacology (Berl) 181: 227-236.

Kelley AE (2004). Memory and addiction: shared neural circuitry and molecular mechanisms. Neuron 44: 161-179.

Langton JM, Richardson R (2008). D-cycloserine facilitates extinction the first time but not the second time: an examination of the role of NMDA across the course of repeated extinction sessions. Neuropsychopharmacol 33: 3096-3102.

Ledgerwood L, Richardson R, Cranney J (2003). Effects of D-cycloserine on extinction of conditioned freezing. Behav Neurosci 117: 341-349.

Ledgerwood L, Richardson R, Cranney J (2004). D-cycloserine and the facilitation of extinction of conditioned fear: consequences for reinstatement. Behav Neurosci 118: 505-513.
Ledgerwood L, Richardson R, Cranney J (2005). D-cycloserine facilitates extinction of learned fear: effects on reacquisition and generalized extinction. Biol Psychiatry 57: 841-847.

Lee JL, Gardner RJ, Butler VJ, Everitt BJ (2009). D-cycloserine potentiates the reconsolidation of cocaine-associated memories. Learn Mem 16: 82-85.

Lu L, Koya E, Zhai H, Hope BT, Shaham Y (2006). Role of ERK in cocaine addiction. Trends Neurosci 29: 695-703.

Makris N, Gasic GP, Seidman LJ, Goldstein JM, Gastfriend DR, Elman I et al (2004). Decreased absolute amygdala volume in cocaine addicts. Neuron 44: 729-740.

Matsuoka N, Aigner TG (1996). D-cycloserine, a partial agonist at the glycine site coupled to $N$-methyl-D-aspartate receptors, improves visual recognition memory in rhesus monkeys. J Pharmacol Exp Ther 278: 891-897.

McGaugh JL, Roozendaal B (2009). Drug enhancement of memory consolidation: historical perspective and neurobiological implications. Psychopharmacology (Berl) 202: 3-14.

Milton AL, Lee JL, Butler VJ, Gardner R, Everitt BJ (2008). Intraamygdala and systemic antagonism of NMDA receptors prevents the reconsolidation of drug-associated memory and impairs subsequently both novel and previously acquired drug-seeking behaviors. J Neurosci 28: 8230-8237.

Norberg MM, Krystal JH, Tolin DF (2008). A meta-analysis of D-cycloserine and the facilitation of fear extinction and exposure therapy. Biol Psychiatry 63: 1118-1126.

O'Brien CP (2003). Research advances in the understanding and treatment of addiction. Am J Addict 12(Suppl 2): S36-S47.

O’Brien CP, Childress AR, McLellan T, Ehrman R (1990). Integrating systemic cue exposure with standard treatment in recovering drug dependent patients. Addict Behav 15: 355-365.

Otto MW, McHugh RK, Kantak KM (2009a). Combined pharmacotherapy and cognitive-behavioral therapy for anxiety disorders: medication effects, glucocorticoids, and attenuated treatment outcomes. Clinical Psychology: Science and Practice (in press [a]).

Otto MW, Tolin DF, Simon NM, Pearlson GD, Basden S, Meunier SA et al (2009b). Efficacy of d-cycloserine for enhancing response to cognitive-behavior therapy for panic disorder. Biol Psychiatry (in press [b]).

Paolone G, Botreau F, Stewart J (2009). The facilitative effects of D-cycloserine on extinction of a cocaine-induced conditioned place preference can be long lasting and resistant to reinstatement. Psychopharmacology (Berl) 202: 403-409.

Platt DM, Carey G, Spealman RD (2005). Intravenous selfadministration techniques in monkeys. Curr Protoc Neurosci Chapter Chapter 9 Unit 9.21.

Platt DM, Rowlett JK, Spealman RD (2000). Dissociation of cocaine-antagonist properties and motoric effects of the D1 receptor partial agonists SKF 83959 and SKF 77434. J Pharmacol Exp Ther 293: 1017-1026.

Platt DM, Rowlett JK, Spealman RD (2001). Modulation of cocaine and food self-administration by low- and high-efficacy D1 agonists in squirrel monkeys. Psychopharmacology (Berl) 157: 208-216.

Quirk GJ, Mueller D (2008). Neural mechanisms of extinction learning and retrieval. Neuropsychopharmacol 33: 56-72.

Ressler KJ, Rothbaum BO, Tannenbaum L, Anderson P, Graap K, Zimand E et al (2004). Cognitive enhancers as adjuncts to psychotherapy: use of $\mathrm{D}$-cycloserine in phobic individuals to facilitate extinction of fear. Arch Gen Psychiatry 61: $1136-1144$.

Roman O, Seres J, Pometlova M, Jurcovicova J (2004). Neuroendocrine or behavioral effects of acute or chronic emotional stress in Wistar Kyoto (WKY) and spontaneously hypertensive (SHR) rats. Endocr Regul 38: 151-155.

Rupniak NM, Duchnowski M, Tye SJ, Cook G, Iversen SD (1992). Failure of D-cycloserine to reverse cognitive disruption induced 
by scopolamine or phencyclidine in primates. Life Sci 50: 1959-1962.

Schneider JS, Tinker JP, Van VM, Giardiniere M (2000). Effects of the partial glycine agonist D-cycloserine on cognitive functioning in chronic low dose MPTP-treated monkeys. Brain Res 860: 190-194.

Thanos PK, Bermeo C, Wang GJ, Volkow ND (2009). D-cycloserine accelerates the extinction of cocaine-induced conditioned place preference in C57bL/c mice. Behav Brain Res 199: 345-349.

Walker DL, Ressler KJ, Lu KT, Davis M (2002). Facilitation of conditioned fear extinction by systemic administration or intraamygdala infusions of $\mathrm{D}$-cycloserine as assessed with fearpotentiated startle in rats. $J$ Neurosci 22: 2343-2351.
Winer B (1971). Statistical Principles in Experimental Design. McGraw-Hill Inc. : New York.

Woods AM, Bouton ME (2006). D-cycloserine facilitates extinction but does not eliminate renewal of the conditioned emotional response. Behav Neurosci 120: 1159-1162.

Yang YL, Chao PK, Ro LS, Wo YY, Lu KT (2007). Glutamate NMDA receptors within the amygdala participate in the modulatory effect of glucocorticoids on extinction of conditioned fear in rats. Neuropsychopharmacol 32: 1042-1051.

Zweifel LS, Argilli E, Bonci A, Palmiter RD (2008). Role of NMDA receptors in dopamine neurons for plasticity and addictive behaviors. Neuron 59: 486-496.

Supplementary Information accompanies the paper on the Neuropsychopharmacology website (http://www.nature.com/npp) 